\title{
El planeamiento urbano como dispositivo
}

\section{Urban planning as a device}

\section{García Bujalance, Susana}

Universidad de Málaga, E.T.S. de Arquitectura. Departamento de Arte y Arquitectura, Área de Urbanística y Ordenación del Territorio, sgbujalance@uma.es

\section{Resumen}

El artículo presenta el planeamiento urbanístico, y en concreto los Planes Generales de Ordenación Urbana, como dispositivos, en el sentido de Michel Foucault. Un dispositivo está formado por un conjunto de prácticas, saberes, instituciones, normativas e incluso arquitecturas, en los que se produce una manipulación de fuerzas. Desde este punto de partida, el planeamiento surge como objeto de análisis de una determinada sociedad, en un determinado contexto histórico, geográfico y cultural. A través del estudio de las leyendas de distintos planes generales de la ciudad de Málaga, considerada como laboratorio para la experimentación gracias al intenso desarrollo urbanístico y económico sufrido en el siglo XX y XXI, se muestra como las leyendas de los planos, en tanto que unión de las determinaciones normativas y la espacialización que se concreta en los planos, suponen un óptimo reflejo del funcionamiento de este dispositivo. El objetivo de este análisis, para los arquitectos y arquitectas que se sientan comprometidos con su tiempo, es aprender el mecanismo de funcionamiento del dispositivo para adquirir la capacidad efectiva de operar en él.

Palabras clave: planeamiento, dispositivo, Foucault, leyenda, sociedad.

\begin{abstract}
The article presents urban planning, and specifically the General Plans of Urban Planning, as devices, in the sense of Michael Foucault. A device is formed by a set of practices, knowledge, institutions, regulations and even architectures, in which produces a manipulation of forces. From this point of view, planning emerges as the object of analysis of a given society, in a particular historical, geographical and cultural context. Through the study of the legends of different general plans of the city of Malaga, considered as a laboratory for experimentation thanks to the intense urban and economic development suffered in the XX and XXI centuries, it is shown as the legends of the plans, as the join of the normative determinations and the spatialization that is concrete in the plans, suppose an optimal reflection of the operation of this device. The aim of this analysis, for architects who feel committed to their time, is to learn the mechanism of operation of the device to acquire the effective ability to operate on it.
\end{abstract}

Key words: planning, device, Foucault, legend, society. 
La hipótesis de esta investigación considera que, a través de los documentos del planeamiento urbanístico sería posible descodificar gran parte de la información cultural, política, social y económica de una determinada sociedad, en un determinado contexto histórico y en un determinado lugar.

Tomar el planeamiento urbanístico como muestra genética de valor para obtener esta información se basa en la consideración del Plan General como dispositivo, en el sentido establecido por Michel Foucault. A continuación expondremos lo que es un dispositivo, el valor que éste tiene como instrumento científico para la crítica social, y la posibilidad de considerar el planeamiento urbanístico como un dispositivo. Una vez expuesto este aspecto, demostraremos con un caso práctico, cómo la leyenda de los planes generales es un método adecuado para el estudio de campo del planeamiento en tanto que dispositivo.

El objetivo de este análisis, para los arquitectos y arquitectas que se sientan comprometidos con su tiempo, es aprender el mecanismo de funcionamiento del dispositivo para adquirir la capacidad efectiva de operar en él.

\section{El planeamiento como dispositivo.}

Foucault, en Saber y Verdad, definió los dispositivos del siguiente modo:

"Lo que trato de situar bajo ese nombre es, en primer lugar, un conjunto decididamente heterogéneo, que comprende discursos, instituciones, instalaciones arquitectónicas, decisiones reglamentarias, leyes, medidas administrativas, enunciados científicos, proposiciones filosóficas, morales, filantrópicas; en resumen: los elementos del dispositivo pertenecen tanto a lo dicho como a lo no dicho. El dispositivo es la red que puede establecerse entre estos elementos heterogéneos. Asi pues, ese discurso puede aparecer bien como programa de una institución, bien por el contrario como un elemento que permite justificar y ocultar una práctica, darle acceso a un campo nuevo de racionalidad. Resumiendo, entre esos elementos, discursivos o no, existe como un juego, de los cambios de posición, de las modificaciones de funciones que pueden, éstas también, ser muy diferentes." (Foucault, 1985, págs. 128-129)

Según Foucault, los dispositivos contienen tres grandes instancias: Saber, Poder y Subjetividad. Éstos no tienen unos límites definidos, sino que varían y se influencian entre ellos. Sin embargo, Foucault murió sin haber concretado su investigación sobre los dispositivos, por lo que resulta más esclarecedor determinar el sentido de éstos, a través del estudio que Gilles Deleuze realiza de la obra de Foucault al respecto.

En su ensayo “¿Qué es un dispositivo?” (Deleuze, 2012) Deleuze explicaba el dispositivo como una madeja de líneas de diferente naturaleza, las cuales siguen varias direcciones configurando procesos en constante desequilibrio. Los dispositivos contendrían según el autor, varias dimensiones. En primer lugar, las curvas de visibilidad y las curvas de enunciación, las cuales muestran en cada dispositivo lo que éste quiere mostrar a través de su propio régimen de luz. Dichas curvas hacen hablar en función de un enunciado previamente establecido, que normalmente, permanece oculto y que sin embargo, determina lo que es dicho y lo que no es dicho.

En segundo lugar, el dispositivo estaría atravesado por líneas de fuerza, formadas por la "dimensión de poder", y la "dimensión del saber", ambas internas al dispositivo y variables con él.

Según Deleuze, Foucault descubre, o más bien intuye, la "línea de subjetivación", la cual

"implica un proceso, una producción de subjetividad en un dispositivo: una línea que debe ir trazándose, en la medida en que el dispositivo le deje o lo posibilite. Se trata de una línea de fuga. Una línea que escapa a las líneas precedentes, que "se" escapa. El Sí mismo no es un saber ni un poder. Es un proceso de individuación que recae sobre grupos o personas y que se sustrae tanto a las relaciones de fuerza establecidas como a los saberes constituidos: como una suerte de plusvalía. No es seguro que todo dispositivo lo incluya" (Deleuze, 2012, págs. 13-14)

Igualmente, Deleuze se pregunta si estas líneas de subjetivación no serán las que faciliten el paso de un dispositivo a otro, anticipando así las líneas de fractura que atraviesan a todo dispositivo, planteando la siguiente reflexión:

"En tanto que las líneas de subjetivación escapan a las dimensiones de saber y poder, parecen particularmente capaces de abrir caminos para la creación, que no cesan de cerrarse, pero también de ser retomados y modificados hasta producirse la ruptura con el antiguo dispositivo" (Deleuze, 2012, pág. 20)

Foucault utilizaba la cárcel o el manicomio como ejemplos de dispositivos, pues ambos están conformados por todas las líneas antes enunciadas: el discurso de una sociedad en torno al delito o la locura cambian a lo largo del tiempo, y están afectados por leyes y reglamentos, proposiciones científicas y morales, instalaciones arquitectónicas, conceptos dichos, y no dichos. En el siglo XIX la locura marcaba a todo aquel que no se adaptaba al sistema, 
ya fuese por enfermedad o por negación de las reglas establecidas. La sociedad los veía como un peligro del que era necesario protegerse para mantener el orden establecido. Las leyes permitían privar de libertad a estas personas y confinarlas en edificios que funcionaban bajo un régimen de vigilancia militar. En definitiva, la sociedad decimonónica rechazaba la locura y a todo aquel que era diferente, en un momento de la historia en el que se estaba construyendo la homogeneización de un sujeto histórico específico: el burgués, y su alter ego, el proletario. Sin embargo, la sociedad actual se caracteriza, según la teoría de sistemas -y en concreto según la adaptación realizada por el sociólogo Niklas Luhmann para la teoría social, a través de toda su obra bibliográfica-, por la relación entre el interior del sistema y su entorno exterior. El entorno produce "irritaciones" en el exterior del sistema, que reverberan en el interior del mismo produciendo sus propias irritaciones. El objetivo de todo sistema es permanecer vivo, por lo que tiende a reducir las irritaciones ajustando sus elementos y funcionamiento interior, para adaptase. Según esta explicación, antiguamente la locura era considerada un elemento del "afuera" y como tal era tratado a través de una arquitectura de carácter carcelario y desplazada por la ordenación de la ciudad al exterior de la misma. Sin embargo, en la actualidad el "sistema mundo", en términos de Immanuel Wallerstein, no puede asumir la expulsión de los enfermos y los disidentes debido a su coste social y económico. Hoy, en un momento histórico caracterizado por la reivindicación de la diferencia a través de la visibilidad de las minorías sexuales y religiosas, el movimiento feminista o la lucha ecologista, el "sistema" no puede asumir mantener fuera de sus límites a toda la cantidad de "inadaptados" al mismo. Por ello la locura ha pasado a ser considerada una enfermedad crónica propia de la sociedad, que debe ser tratada dentro de ella. Las personas que sufren trastornos o inadaptación no son privadas de su libertad, no son consideradas diferentes a los demás, ni son excluidas del conjunto social. La legislación las protege y las considera personas enfermas capaces de tomar decisiones propias, prevaleciendo el sujeto "personas" sobre el predicado "enfermas". Así mismo, de manera generalizada la sociedad ve en la esquizofrenia, la depresión, la anorexia o la bipolaridad, una cuestión asumible dentro de la cotidianeidad, y el lenguaje se ha adaptado dejando de hablar de locura para hablar de salud mental. La arquitectura por su parte, responde a este nuevo paradigma a través de unos edificios amables que el urbanismo integra en la ciudad, y el sistema sanitario los incluye dentro de hospitales y centros de salud de barrio, ofreciendo una estética de normalidad acorde a la necesidad de hacerlo normal.

Nuestra hipótesis es que el planeamiento urbanístico, en tanto que disciplina técnica para la construcción de la ciudad, es un dispositivo formado por saberes culturales, prácticas sociales, vectores económicos, normativas y reglamentaciones, instituciones e incluso edificios, presupuestos morales y enunciados científicos que cambian a lo largo de la historia, representando a una sociedad dada. Estudiando el dispositivo "planeamiento", comprobamos la influencia que se ejerce sobre la sociedad en cada momento histórico. Por ejemplo, si el planeamiento general se consideró durante los años de la Transición Democrática en España un modo de luchar contra el centralismo estatal imperante, y fue tratado como una auténtica constitución municipal (Leira, 1989), hoy existe un recelo generalizado hacia los planes generales, debido a la compleja tramitación administrativa que conllevan y a la dificultad para considerar este instrumento como una herramienta efectiva para mejorar la vida de la ciudadanía.

Volviendo a Deleuze y a su definición de lo que es un dispositivo, éste escribió:

"Discernir las líneas de un dispositivo supone, en cada caso, trazar un mapa, cartografiar, medir un territorio desconocido, y a eso se le denomina "hacer trabajo de campo"'” (Deleuze, 2012, pág. 10)

A continuación se propone hacer lo suyo, hacer un trabajo de campo cartografiando un territorio conocido. En este caso, el análisis de la evolución del planeamiento de la ciudad de Málaga, desde sus orígenes hasta ahora. El estudio de este caso resulta oportuno porque, además de ser una de las ciudades en las que más planeamiento se ha elaborado a lo largo de su historia, Málaga puede considerarse un óptimo laboratorio para analizar procesos que si bien se han producido en todas las ciudades españolas, en esta ciudad se han dado con más intensidad debido a la gran inversión económica que se ha producido en su territorio.

Aunque a continuación vamos a estudiar las cartografías históricas de Málaga como antecedente a lo que es propiamente el planeamiento urbanístico, entendemos que éste se puede considerar como tal a partir del siglo XX, y en concreto a partir de su segunda mitad, con la aprobación de las primeras leyes del suelo europeas, como la española de 1956. En este momento se produce un punto de inflexión histórico importante en el caso de España, que permite visibilizar lo que tratamos de demostrar. Para ello es necesario dar un salto en el tiempo y recordar cómo tras un primer rechazo ideológico, el turismo pasó a ser considerado por el Régimen de Franco como un instrumento potente para equilibrar la balanza de pagos. La compra de energía y tecnología en el exterior no se compensaba con la venta de cítricos y productos agrícolas. Sin embargo, las divisas dejadas en España por los turistas permitieron este equilibrio sin necesidad de producir bienes y servicios que exportar. Esto favoreció una industria de las infraestructuras con el objetivo de hacer accesibles los destinos turísticos y la movilidad generada por esta economía. Esta forma de economía favoreció un aprendizaje de la sociedad en torno a la explotación de 
estos recursos, y una nueva forma de relación entre agentes públicos y privados, locales y nacionales, en torno a la construcción de obras e infraestructuras. Toda una red de relaciones, prácticas y normas que constituyeron un auténtico dispositivo en relación al desarrollo inmobiliario. Este proceso se dio de manera más o menos generalizada en todos los territorios litorales de la península y las islas, modificando el coste de unos suelos que a priori no tenían valor estratégico para la anterior política industrial y agrícola del Régimen. En el caso de Málaga esta transformación fue especialmente acusada gracias a la influencia del intenso desarrollo turístico de la Costa del Sol.

Esta investigación trata de hacer el trabajo de campo mencionado por Deleuze, en relación al dispositivo "Planeamiento urbanístico".

Para ello veremos como a través de un análisis crítico del lenguaje normativo y gráfico de los documentos del planeamiento urbanístico, es posible realizar un trabajo de campo que nos permitirá obtener información de la sociedad que queremos comprender, tomando como hipótesis que el planeamiento es un dispositivo muy potente que convoca en torno a sí un conjunto heterogéneo de prácticas y saberes, normativas e instituciones, enunciados filosóficos y proposiciones éticas. Para ello, utilizaremos la leyenda como instrumento eficaz de análisis, pues es ahí donde se encuentran los lenguajes normativo y gráfico del Plan.

\section{Los antecedentes.}

Aunque nos vamos a centrar en los documentos de planeamiento general de la ciudad de Málaga, no queremos aproximarnos a ellos sin hacer un breve repaso a planos y planes anteriores a lo que podríamos denominar "planeamiento urbanístico general".

Comenzaremos por el "Plano de la ciudad de Málaga, de su Alcazaba, Castillo Gibralfaro y su puerto conforme estaban en el año 1487 en que la entregaron los moros a los Reyes Católicos" de 1862, atribuido a Guillén Robles, donde encontramos unas pocas trazas y una escueta leyenda que indica los lugares estratégicos de lo que se entendía que fue la ciudad de Málaga antes de la toma de la misma por los Reyes Católicos. En este plano hallamos los datos que interesaban en ese contexto: la muralla y su ampliación, los montes, los cultivos de las productivas huertas del exterior amurallado, y la localización de algunas edificaciones importantes como la alcazaba amurallada. El río apenas aparece marcado por una línea de lo que parecen ser árboles, con un ancho constante en todo su trazado.

En el plano para la construcción de la ampliación del Puerto de la ciudad, el ingeniero Bartolomé Thurús dibujó en 1717 datos propios del interés del ejército en ese momento: la cuidad y sus murallas, las construcciones más importantes, los enclaves militares estratégicos, los montes y las áreas cultivables, y por primera vez, el río Guadalmedina con una especial relevancia y realismo. En aquel momento las riadas sucesivas producidas por la deforestación de los montes de Málaga ya se habían convertido en un problema de gran importancia. Muestra de ello fue la orden dada por Carlos I en 1523, prohibiendo a las gentes abandonar la ciudad ante el temor de inundaciones producidas por el río (Álvarez Calvente, 1973).

En el proyecto para desviar el río Guadalmedina del ingeniero militar Próspero Verdom, hacia 1723 observamos algo más que murallas, cultivos y lugares estratégicos. La ciudad necesitaba crecer, y los caminos de conexión con el territorio pasan a adquirir una importancia estratégica en su relación con el río desviado y la conexión con los territorios de influencia. El desvío nunca llegó a producirse.

En el plano de Málaga que recoge la distribución de la epidemia de fiebre amarilla, de Onofre Rodríguez de 1805, vemos la distribución de barrios y distritos con el número de infectados, así como la leyenda que los identifica. El plano, por primera vez, se convierte en la representación gráfica de un mecanismo de control de la población y unos atributos concretos: la infección por fiebre amarilla.

El "Plano de la ciudad de Málaga", realizado por el capitán del Estado Mayor del Ejército, Joaquín Pérez Rozas en 1863, muestra la definición gráfica de la ciudad, o de lo que se entendía en ese momento como la ciudad: manzanas, calles con sus nombres, topónimos de áreas limítrofes, edificios y espacios públicos representativos, y la infraestructura del ferrocarril, obra pública realizada por la sociedad civil con el objeto de abastecer de materia prima las incipientes industrias localizadas en la margen derecha del río Guadalmedina. Cuando la muralla dejó de tener sentido defensivo y la ciudad adquiere un valor propio como tal, más allá de su posición militar o estratégica en el territorio, los elementos propiamente urbanos como los espacios públicos y las infraestructuras, adquieren el protagonismo propio del tiempo histórico que se vive: el resurgimiento de una nueva clase urbana burguesa, y en el caso de Málaga, industrial y comercial.

En el "Plano de ampliación del puerto" de José Valcárcel (1895), el énfasis en la representación se concreta en el 
loteo de las manzanas resultantes de la nueva ordenación que se proponía con la ampliación del puerto. La necesidad de un mayor calado en el puerto, cada vez menos profundo debido a los sucesivos aportes de tierra del Guadalmedina, hicieron necesario llevar el puerto mar adentro, con el consiguiente relleno de toda la zona del arenal del antiguo puerto. Ello suponía una importante obra de infraestructura que debía financiarse con la venta de solares del área de crecimiento resultante. En este caso no se definen los hitos, ni la conexión con el territorio, ni las calles ni los espacios públicos. Es el loteo de las parcelas resultantes, así como la definición de las obras del puerto lo que se representa en el plano.

En el proyecto “Larios" para el parque de la ciudad de Málaga de 1897, fecha próxima a la del plano de ampliación del puerto, se dibuja el Parque de Málaga resultante del relleno del puerto de levante, al igual que el puerto de poniente con su loteo de parcelas para venta. Pero en este caso, el marqués de Larios quiso regalar esta obra como agradecimiento a la ciudad. O más bien como agradecimiento a las grandes plusvalías obtenidas por la construcción de la calle Larios, calle céntrica de la ciudad cuyos terrenos se obtuvieron como consecuencia del proceso de desamortización, y que permitió realizar a la familia Larios el primer ensayo de lo que sería una próspera actividad inmobiliaria que se continúa hasta la fecha a través de la Sociedad Azucarera Larios, S.A. El objeto de la obra era el mismo: llevar el puerto hacia el interior de la bahía y ganar metros de tierra en el frente marítimo de la ciudad. Pero mientras el plano de la ampliación del puerto hacía énfasis en el loteo de parcelas resultantes, el plano de Larios incide en la definición gráfica del gran espacio público que el marqués ofrecería a la ciudad de Málaga, y a su conexión con el resto de la ciudad existente.

El primer plan urbanístico de la ciudad propiamente dicho, es el Plan de Ensanche de Moreno Monroy de 1861 (Fig.1). En él podemos observar las trazas de la ciudad existente y el dibujo de lo que pretendía ser la ciudad del futuro, con la definición de un ensanche al oeste del río Guadalmedina, y un intento de ensanches parciales en el interior de la ciudad histórica.

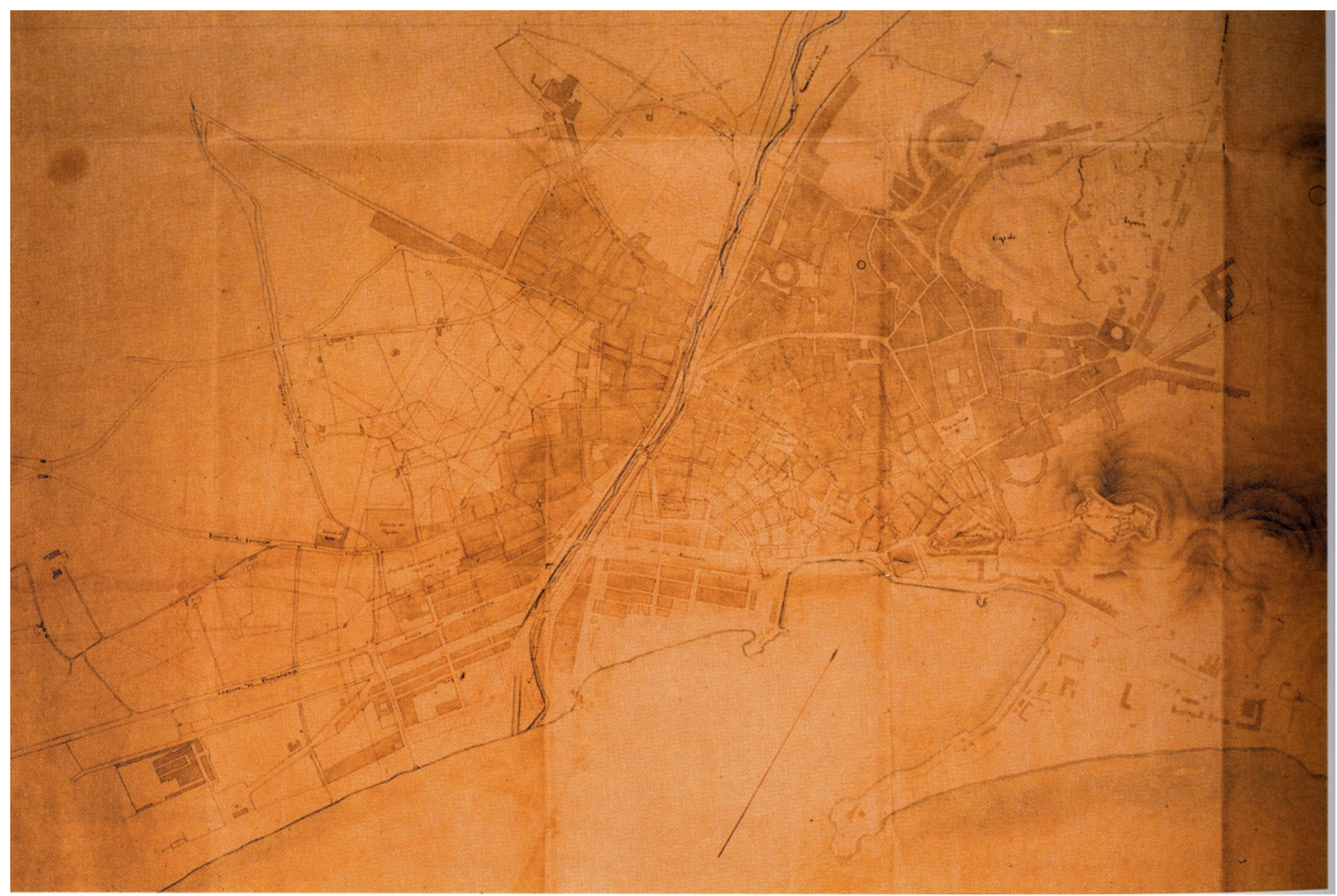

Fig.1 Plan de Ensanche de Moreno Monroy. 1861.

El siguiente Plan de Ensanche que se realiza para la ciudad de Málaga, es el de José María de Sancha y dibujado por Emilio de la Cerda en 1892. En este plano, comprensivo de toda la ciudad al igual que el de Moreno Monroy, se dibuja la ciudad existente con su definición de manzanas y espacios públicos, así como las trazas de lo que se 
proponía como crecimiento de la ciudad. Como diferencia con respecto a aquel, se dibujan las propuestas del Paseo del Parque y el puerto, así como un ensanche sobre el río Guadalmedina, desviado según la propuesta de Próspero Verdom de 1723.

Podemos decir que este Plan y el de Moreno Monroy, ambos de la segunda mitad del siglo XIX, son planes urbanísticos propiamente dichos, ya que participan de unas herramientas propias del urbanismo y el planeamiento, gracias a la instrumentación técnica y jurídica -en cuanto a las expropiaciones y reparcelaciones- desarrollada por planes como la reforma de París de Hausmann o el Plan de Ensanche de Barcelona de Cerdá. Sin embargo, la leyenda en este momento es aún escasa, pues el dibujo se centra en representar la forma urbana de la cuidad existente -manzanas, edificios singulares en algunos casos, y espacios públicos-, y en dibujar sobre ella las propuestas acordadas por los poderes políticos y económicos de la época.

En 1924, al albur del Estatuto Municipal del 8 de marzo de 1924 decretado por Primo de Rivera, los Ayuntamientos encuentran una herramienta que les dota de independencia, y también de responsabilidad sobre el urbanismo en sus ciudades. Con la obligación de redactar un Plan de Ensanche, el Ayuntamiento de Málaga encarga a los ingenieros municipales Bores, Lombardo, Benjumea, Giménez y Werner, un Plan de Grandes Reformas en el que se dibujan por primera vez las trazas de la ciudad futura, pero sobre todo las infraestructuras existentes y necesarias para el crecimiento y la mejora de la ciudad (Fig.2). En una época en la que la ciudad se ha convertido en un artefacto cada vez más difícil de manejar, en el que la concentración de población exige de una planificación de infraestructuras y un plan de higiene, el plano representa con especial concreción las actuaciones necesarias en materia de infraestructura, apertura de calles, saneamiento, etc. La definición de manzanas y calles es sólo la base sobre la que dibujar y planificar estas reformas que la ciudad del inicio del siglo necesitaba.

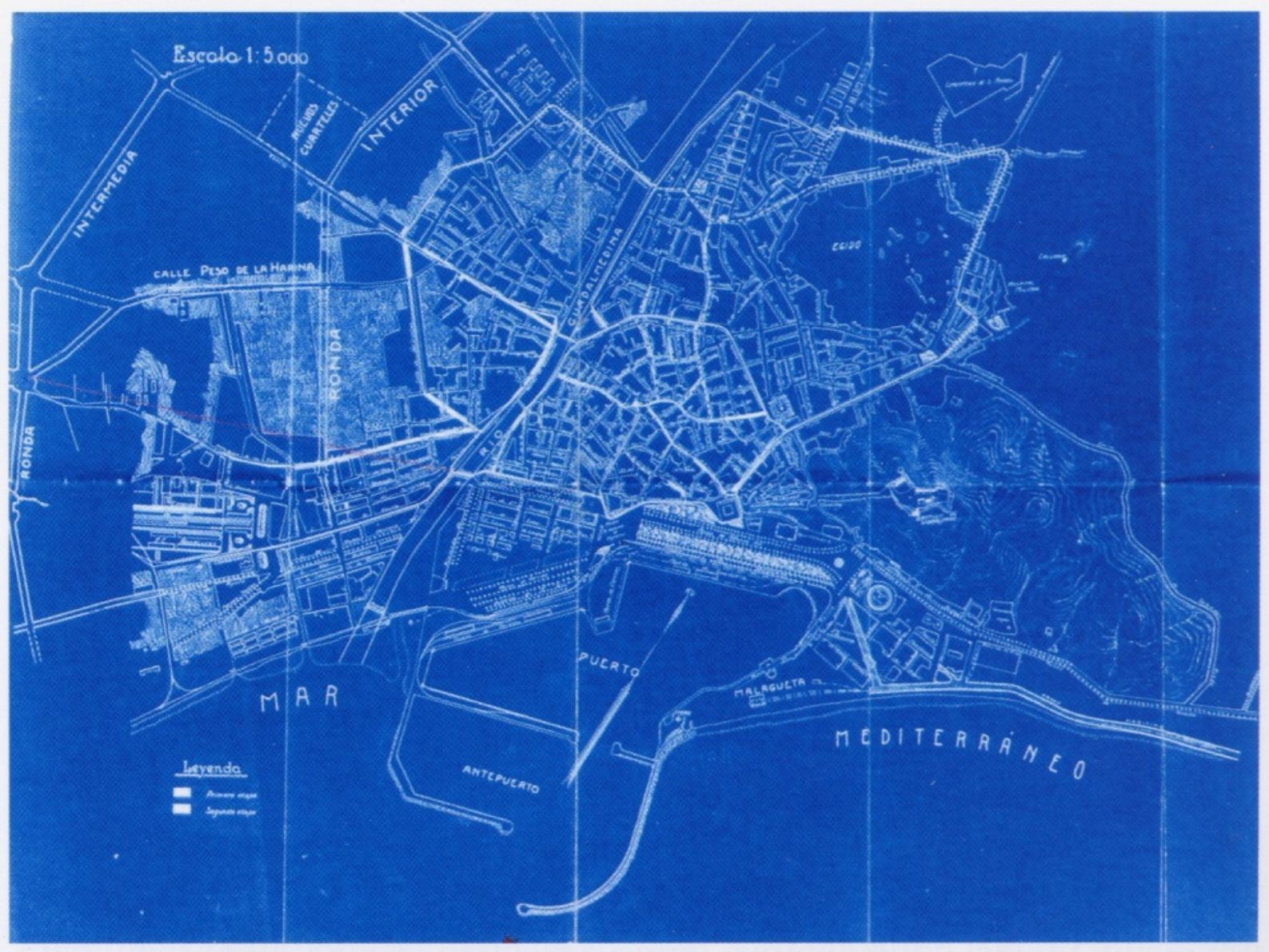

Fig.2. Plan de Grandes Reformas. Lombardo, Benjumea, Giménez y Werner. 1924.

En 1929, el arquitecto municipal Daniel Rubio realiza un Plan de Ensanche, como continuación del Plan de Grandes Reformas de 1924. En él encontramos una lectura totalmente diferente a la que hicieron los ingenieros anteriores. 
La ciudad necesitaba ser proyectada, no sólo reformada. Y esto es precisamente lo que representan los dibujos de este Plan de Ensanche. Sin embargo, pierde el concepto de escala, y trata de llevar las trazas propias de las grandes ciudades europeas y americanas a una ciudad cuyo tamaño era insuficiente. En todo caso, el Plan de Daniel Rubio refleja otras preocupaciones diferentes a las de los mencionados ingenieros. Se representan espacios públicos de nueva planta, usos, y el trazado de la conexión entre la ciudad existente y la ciudad futura, contando con los caminos históricos de penetración en el territorio como elementos de articulación del crecimiento. El grado de representación, si bien sigue siendo escaso, comienza a mostrar la preocupación de una sociedad por la forma y la imagen de la ciudad, más allá de la forma y la imagen de su arquitectura representativa.

Es en el Plan de González Edo de 1950 (Fig.3), el primer Plan en el que podemos hablar de la leyenda propiamente dicha, pues es a partir de entonces cuando el planeamiento adquiere un valor de transmisión de ideas más allá de los técnicos y los poderes que promovían las transformaciones urbanas. El crecimiento de las ciudades debía ser participado por más agentes. El urbanismo tenía implícita una función social que exigía poner por encima de los intereses particulares, los intereses de la propia ciudad, tal y como se indicaba en la exposición de motivos de la ley del suelo de 1956, que se encontraba en proyecto durante la etapa de redacción del Plan de 1950. Esta ley reflejaba el "espíritu de los tiempos" respecto a la necesidad de ordenar, reconstruir y transformar la ciudad, y de incorporar a los propietarios de suelo en el proceso.

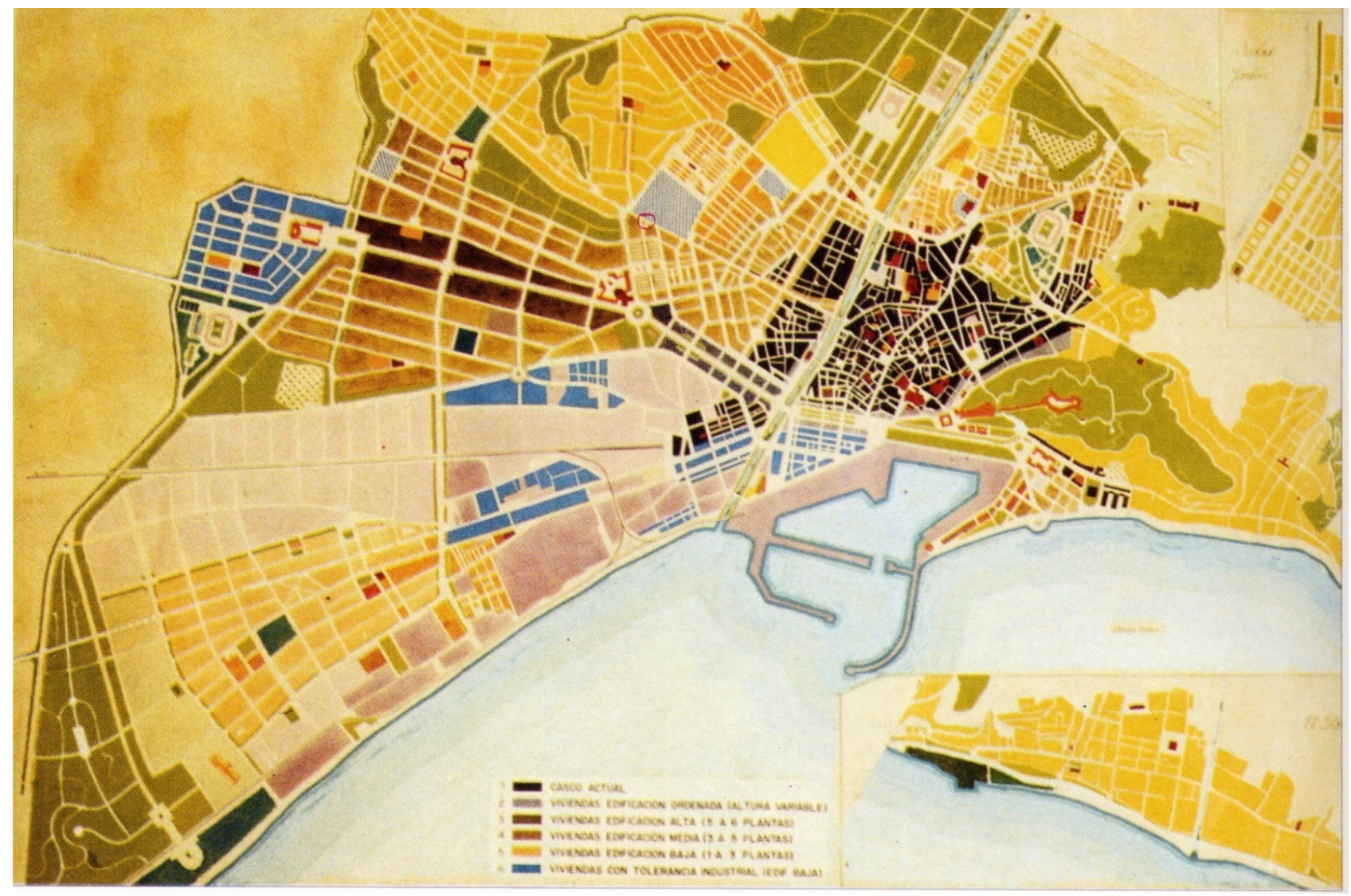

Fig.3. Plan General de Málaga. González Edo. 1950.

En el Título III de la Exposición de Motivos de la Ley del Suelo de 1956 podía leerse:

"El régimen jurídico del suelo encaminado a asegurar su utilización conforme a la función social que tiene la propiedad, resulta el cometido más delicado y difícil que ha de afrontar la ordenación urbanística. Y se impone sin embargo, efectuarlo, precisamente porque si la propiedad privada ha de ser reconocida y amparada por el Poder público, también debe armonizarse el ejercicio de sus facultades con los intereses de la colectividad" (España, 1956, pág. 3106)

En un momento en el que era imperioso construir viviendas para la población saliente de la Guerra Civil, la administración del Régimen se vio incapaz de construir el parque inmobiliario necesario. Por ello se requería implicar a 
los propietarios de suelo y a los promotores inmobiliarios en esta labor. Los planes generales debían ser un instrumento que convocase en torno a sí a todos estos agentes, permitiendo la consulta por parte de todos ellos, así como de los organismos sectoriales principales encargados del desarrollo de infraestructuras de carácter estatal o de complejos productivos establecidos por el propio Régimen. Aunque en este momento aún no estaba articulado el texto de la ley, la Ley del suelo de 1956 contemplaba un procedimiento de exposición al público en el que participarían los agentes implicados: organismos de la Administración, propietarios de suelo y promotores.

"Si ideal en la empresa urbanística pudiera ser que todo el suelo necesario para la expansión de las poblaciones fuera de propiedad pública, mediante justa adquisición, para ofrecerle una vez urbanizado, a quienes desearen edificar, la solución, sin embargo, no es viable en España. Requeriría fondos extraordinariamente cuantiosos que no pueden ser desviados de otros objetivos nacionales, y causaría graves quebrantos, a la propiedad y a la iniciativa privadas" (España, 1956, pág. 3107)

La ley introdujo un nuevo derecho estatutario de la propiedad que ya no era ilimitado sino que dependía de unas obligaciones definidas a priori por la propia Ley y por los planes. Para legitimar este nuevo derecho, se introdujo la posibilidad de que entidades y propietarios pudieran formular avances de Plan y anteproyectos parciales que se tendrían en consideración en la redacción de los Planes Generales, así como la obligatoriedad de exponer al público los documentos urbanísticos y la citación personal para la información pública a los propietarios de los terrenos afectados. Así mismo se incluyó junto con la figura de la gestión por expropiación, la participación con la Administración en el sistema de cooperación y la gestión absoluta de los agentes privados en el sistema de gestión por compensación.

Era necesario por tanto, hacer inteligibles los contenidos del plan a una población más amplia que la de los propios técnicos municipales o del Estado, a quienes por otra parte se les podía explicar directamente aquello que no entendiesen. Esta es la idea que subyace en el cambio de unos planos de Ensanche que sólo necesitaban ser comprendidos por los agentes que participaban de la transformación del a ciudad, a un modelo más plural. Podríamos concluir que la inclusión de leyendas claras en los planes urbanísticos, explica el ascenso de la sociedad industrial al poder, durante el siglo XX. El modelo capitalista exigía un estatuto contractual propio de un escenario comercial abierto y controlado en mayor medida por los poderes económicos frente a los exclusivamente políticos u oligárquicos.

Así, nuestra investigación sobre trabajo de campo -que diría Deleuze-, comienza realmente en este punto. Es a partir de ahora cuando adquiere especial sentido el estudio crítico del grafismo en los planos de los Planes Generales y de su leyenda, entendidos desde su instrumentación por parte del dispositivo "Planeamiento". Consideramos la leyenda como prueba diagnóstica, en tanto que ésta representa el punto de unión entre la normativa y la espacialización que la propuesta realiza. Todo proyecto lleva implícita la definición de unos conceptos (manzana, uso, altura...), y una normativa asociada que lo regula (normas, reglamentos, ordenanzas...). La leyenda es el punto en el que ambas se encuentran. Lo que nos interesa no es la espacialización de las propuestas, ni tampoco la concreción de su normativa. Lo que buscamos en la leyenda es el vector de la sensibilidad de una época, los agentes que participan, las líneas de poder implícitas o explícitas, y el lenguaje en el que una sociedad se reconoce o al que se enfrenta.

\section{La leyenda como expresión del dispositivo.}

En este apartado analizamos algunos de los lenguajes propios del planeamiento urbanístico general en la ciudad de Málaga a partir de su Plan de 1950.

En este Plan, propio del contexto autárquico anterior al II Plan de Estabilización de 1959, se dibuja la ciudad existente y sus propuestas de crecimiento con un grafismo elaborado y exquisito, propio de una cultura moderna aprendida por su redactor en estancias en el extranjero (Seguí Pérez, 1988)

En la leyenda del plano de propuesta que se conserva, podemos encontrar una categorización de tipologías arquitectónicas, en las que se reconoce el caserío existente y las nuevas propuestas, con definición de alturas. Importaba la imagen de la ciudad, e importaba el modo en que esta imagen debía ser transmitida.

El siguiente Plan, de 1971 (Fig.4) se redacta bajo la influencia de la Carta de Atenas, cuando ya en los ambientes más avanzados de la cultura urbanística europea se estaba produciendo una fuerte crítica hacia el modelo funcionalista de la zonificación. Lo cierto es que el Plan no pretende ninguna lectura comprensiva de la ciudad, quizá porque se redacta en plena vorágine de un modelo basado en el trinomio "valoración del suelo, promoción y construcción", como un ciclo infinito apoyado en una demanda inmobiliaria ilimitada. Con la derogación del Plan General de 1950 de González Edo por Orden Ministerial en 1964, la ciudad se quedó huérfana de una mínima normativa 
que situase la acción de los promotores y constructores. Por ello, en una escena de auténtica anarquía urbanística, lo que el Plan de 1971 pretendía era normativizar jurídicamente la desinhibida acción de los agentes inmobiliarios, otorgando a la acción inmobiliaria un marco jurídico fiable.

Aquel Plan de 1971 es el reflejo de su tiempo, y considera en su grafismo los conceptos propios de esa época: clasificación, estructura viaria principal, zonificación y superficies de expansión. Incluso en la estructura viaria, existe un lenguaje que muestra cómo el proyecto de la Red Básica estatal y otros proyectos ministeriales se superponen a la ciudad a través del vacío que refleja el dibujo. Existía una clara falta de comunicación entre el poder central y la gestión local. Por ello, los temas tratados por el Plan, son aquellos que se reflejan en la memoria y en la leyenda de los planos: clasificación, edificabilidad, altura de la edificación, funcionalidad viaria, zonificación y ordenanza como objetivación de las posibilidades inmobiliarias de los proyectos por hacer. Es a fin de cuentas, un intento de dar forma jurídica al modo en que se había venido construyendo en la ciudad desde que en 1964 quedara suspendido el Plan de González Edo por su incapacidad para articular el brutal crecimiento sobrevenido en Málaga. Es la objetivación a través de un documento administrativo, del lenguaje del mercado inmobiliario en el urbanismo, atendiendo a su código normativo específico, donde la "forma o estructura" de la ciudad se define por los datos cuantitativos como única acción de la planificación, al margen de la realidad urbana de la ciudad.

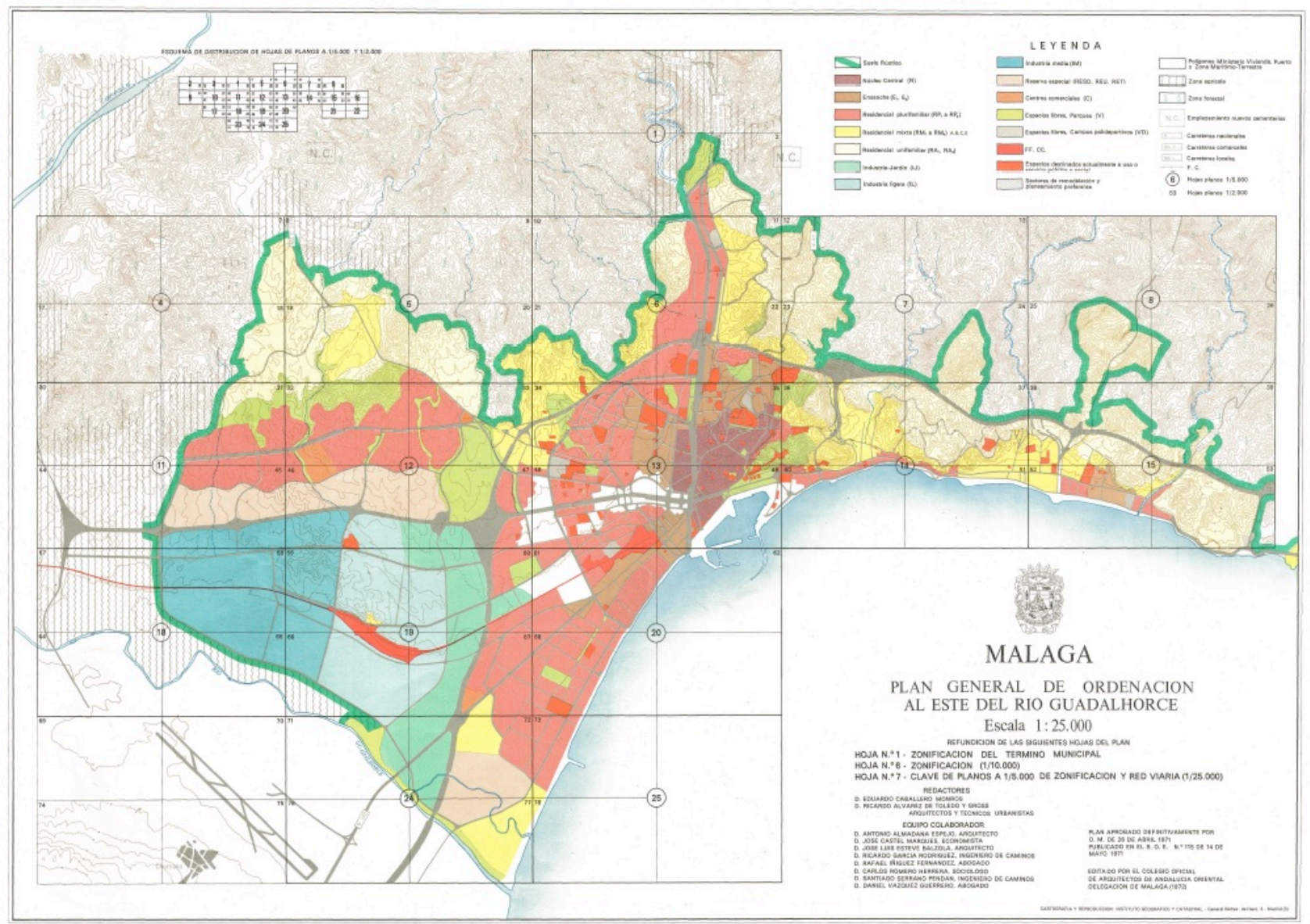

Fig.4. Plan General de Málaga. Eduardo Caballero y Ricardo Álvarez de Toledo. 1971.

Bajo el epígrafe de "organización" en la leyenda (Fig.5) encontramos los siguientes conceptos: los "parques", en una concepción sistémica de los parques periurbanos de las áreas de crecimiento; los "jardines", como vestido de las áreas de recreo propias de la ciudad histórica; los "Campos de Deporte", que normalmente son campos de fútbol, no tienen la concepción de "áreas deportivas"; el uso "culto" refleja el pacto de la Iglesia Católica con el Régimen de Franco; los mercados aparecen como lugares de abastecimiento de la población pues debían ser garantizados en las áreas de crecimiento; el uso "higiene y sanidad" verbaliza la visión higienista del crecimiento de las ciudades, mientras que el de "espectáculo" surgido de la actividad turística, es el reflejo de una época; el 
"comercio no molesto" o los "servicios molestos" instan a preguntar para quién es molesto y en qué sentido (¿molestia ambiental, sonora o moral?)

En el plano de clasificación y calificación, encontramos referencias al "suelo rústico" explicitando lingüísticamente la idea aún arraigada de la diferencia entre el campo y la ciudad: lo rústico y lo urbano. El suelo que no se edifica es rústico, forestal o agrícola. En la leyenda, el suelo de "ensanche" verbaliza el ideario desarrollista y extensivo propio de los años 60 . El suelo de crecimiento se denomina de "reserva", expresando claramente la concepción desarrollista que lo "proyecta" hacia el futuro como el suelo que seguirá siendo consumido.

En las ordenanzas encontramos una única categoría para los edificios históricos. Así, el "núcleo central" incluye toda clase de edificaciones enclavadas en el centro histórico, entendido éste como una unidad sobre la que no se reflexiona su forma, contenido o simbolismo. Las ordenanzas de crecimiento "unifamiliar", "plurifamiliar" o "mixto", contienen un sentido programático, no analítico, enfocado a la construcción de nuevos edificios.

La actividad productiva se nombra como "Industria Jardín", "Industria ligera" e "Industria media”. Se refleja así, la incapacidad del territorio para absorber una actividad industrial propia de otras ciudades desarrolladas en aquella década, que sí albergaban auténtica "industria pesada". Pero esta nomenclatura también muestra la concepción de lo productivo en tanto que "industrial" para la fabricación de cosas.

Los centros comerciales aparecen en el panorama nacional en aquel momento, y así se refleja en la leyenda. Un nuevo concepto comercial que adquiere su "verbalización" en la planificación urbanística gracias a su reconocimiento en la leyenda.

Las infraestructuras contempladas son las del Ferrocarril y las distintas carreteras locales, comarcales o estatales. Las cuestiones sectoriales que se reflejan son la línea de delimitación del dominio marítimo terrestre, el puerto y los polígonos del Ministerio de Vivienda.

Los espacios destinados a servicios evidencian quizá, mejor que ningún otro apartado de la leyenda, una concepción propia de la época y del enfoque sistémico del urbanismo adoptado por el equipo redactor. Éstos se nombran como "dotaciones" y "servicios", al modo de una infraestructura de agua o saneamiento.

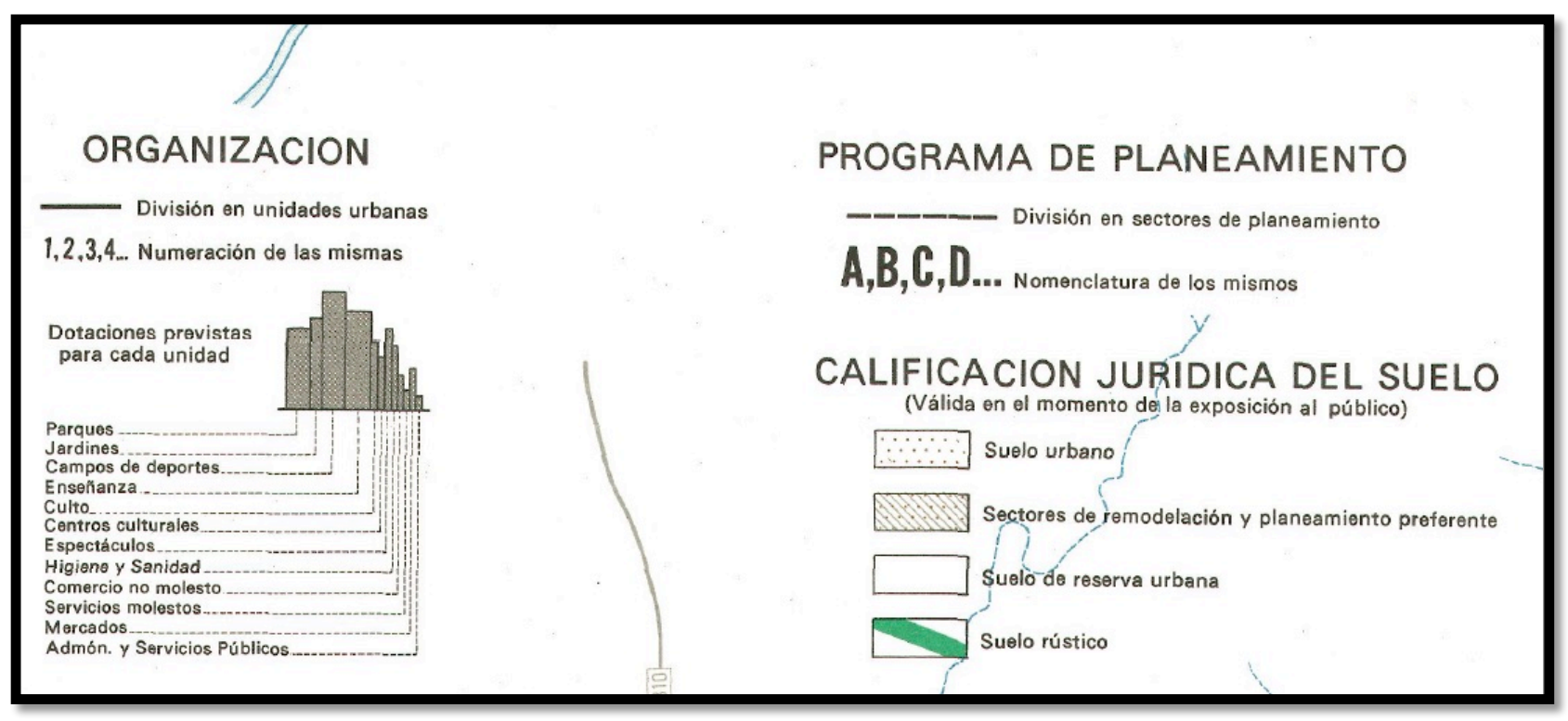

Fig.5 Fragmento de la leyenda del Plan General de Málaga de 1971.

Durante el desarrollo de la década de los 70, el clima social fue cambiando. La falta de infraestructuras y dotaciones, así como una ciudadanía más consciente de su condición -en gran medida por la influencia de los turistas que venían de países democráticos-, hizo que un nuevo derecho que Lefebvre y otros intelectuales de la época habían nombrado como "derecho a la ciudad", tomase forma a través de las reivindicaciones de los movimientos vecinales. Se demandaban espacios públicos como lugares para la convivencia ciudadana, equipamientos públicos y la generación de un entorno urbano adecuado para la vida en la ciudad.

Muchos arquitectos de aquella época, comprometidos con los movimientos políticos y ciudadanos de izquierdas, 
pasaron a la acción a través de su asesoramiento a movimientos vecinales en proyectos de reforma urbana promovidos por unos Ayuntamientos, que ya mostraban la debilidad de un Régimen que se desmoronaba. Se acuñó en aquel momento el concepto de "hacer ciudad" como principal objetivo del urbanismo. Era lo que Manuel Solá Morales denominó "el urbanismo urbano""

En una situación de caos urbanístico formal y procedimental, y como consecuencia del relevo gubernamental que se produjo en 1969 en el país, se inició un periodo de análisis crítico de esta etapa que había llegado ya a una situación insostenible. Se inició así la reforma de la Ley del Suelo de 1956, que dio como resultado la Ley del Suelo de 2 de mayo de 1975. Esta Ley, preconstitucional y elaborada durante los primeros años de la década de los 70 por los "tecnócratas" de la última etapa del Régimen de Franco, se integraba dentro de la visión del tercer Plan de Desarrollo 1972-1975, que se alejaba de la política de polarización anterior, industrial y turística, para proponer un modelo de integración regional con un mayor horizonte temporal. Se comprendió en este momento, y esta es la cualidad de la que también participa la reforma de la Ley del suelo, que las políticas territoriales necesitaban enfoques temporales más amplios.

Como novedad, esta ley incluía la preocupación por el patrimonio y los problemas ambientales, influenciada por el Informe de Roma de 1971 sobre los problemas ambientales derivados de una economía basada en el petróleo y el consumo de recursos, y por la Convención sobre la protección del Patrimonio Mundial, cultural y natural de 1972. Ambos concretan una nueva preocupación global que la Ley del Suelo recoge en su articulado, a través de las directrices de los Planes Directores, y de la propia regulación de los Planes Especiales. Gracias a la inclusión de estos conceptos en el articulado legal, las curvas de enunciación de las que hablaba Deleuze, enuncian estos dos nuevos conceptos, visibilizándolos por medio del desarrollo normativo de la Ley, a través de la redacción de los planes generales de aquella etapa.

Así, llegamos al Plan General de Málaga de 1983 (Fig.6), primer Plan de la Democracia. El primer equipo de gobierno municipal elegido democráticamente encargó el Plan General a los arquitectos que habían formado parte de ese movimiento vecinal activo durante la década anterior. El asesoramiento de Proyectos como el de la reforma urbana del barrio histórico de Trinidad-Perchel fue un ensayo que permitió a los tres arquitectos directores del Plan, Salvador Moreno Peralta, Damián Quero y José Seguí, acometer una tarea de reforma y proyectación urbana comprometida con la ciudadanía. El Plan, redactado desde el propio Ayuntamiento en la Oficina del Plan General, y determinadamente apoyado por el equipo de gobierno, se aprobó en cuatro años desde su inicio, a partir de una ley, la Ley del suelo de 1975 y los reglamentos de 1978, que no habían sido antes aplicados.

\footnotetext{
${ }^{1}$ La mejor referencia contemporánea de esta idea la encontramos en los números del 1 al 6 de la Revista Ur, del Laboratorio de Urbanismo de Barcelona.
} 


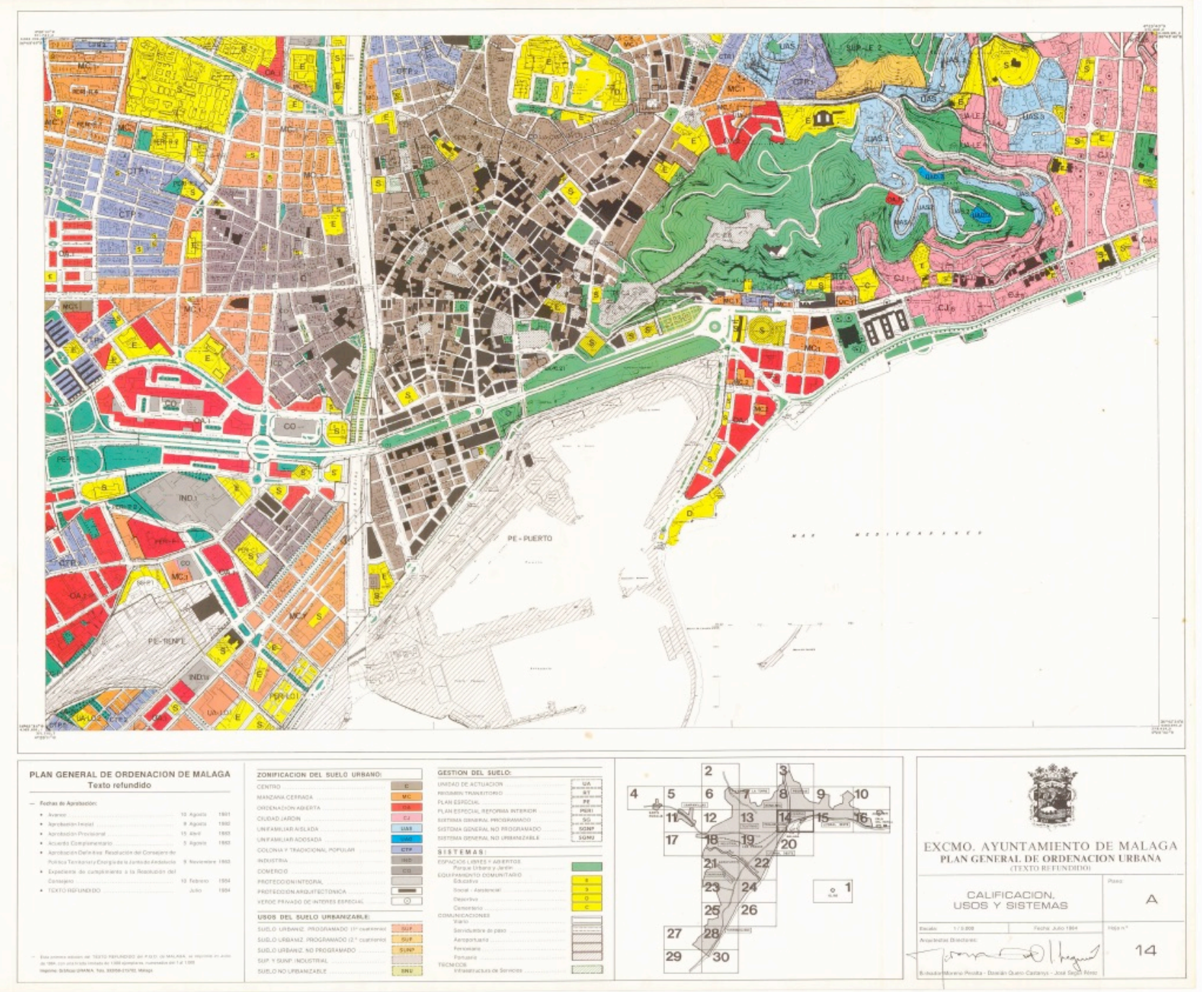

Fig.6 Plan General de Málaga. Damián Quero, Salvador Moreno y José Seguí. 1983.

El Plan de 1983 supuso un punto de inflexión en el planeamiento urbanístico español, y también en la cultura urbanística, pues conjugó en torno a sí a los mejores y más relevantes urbanistas de aquella etapa, y que fue reconocido con el Premio Nacional de Urbanismo de 1985. No en vano, Manuel Solá Morales y Eduardo Leira, fueron nombrados asesores del equipo redactor.

Podemos decir además, que el plan de 1983 fue el primer plan en el que se ensayó un modelo de planificación urbanística en el que el poder político, la capacidad técnica de sus arquitectos y la voluntad vecinal, actuaron conjuntamente modificando las líneas de acción propias de las prácticas inmobiliarias en las que se habían situado los vectores del poder político del Régimen y la oligarquía económica de la sociedad española (García Bujalance, 2016). Las líneas de subjetivación de las que hablaba Deleuze en su interpretación de Foucault, habrían actuado en este caso de un modo explícito y determinante.

Analizando la planimetría del Plan General de 1983, encontramos una mayor diversificación de los colores de las ordenanzas sobre el suelo urbano (Fig.7). El influjo cultural de la Tendenzza italiana, llegada a los redactores del Plan a través de la influencia de Manuel Solá Morales, se materializa en una calificación que prima lo local, la cultura de la recuperación y la delimitación del espacio público. Incluso en las áreas de extensión, encontramos una gran definición de las trazas urbanas, desconfiando de las posibles soluciones que se pudieran dar con posterioridad, al margen de la concepción global de la cuidad. Si el Plan de 1971 fue un plan de extensión programática, el Plan de 1983 tuvo como objetivo la reconstrucción de la ciudad existente. 


\begin{tabular}{|c|c|}
\hline \multicolumn{2}{|c|}{ ZONIFICACION DEL SUELO URBANO: } \\
\hline CENTRO .............. & C \\
\hline MANZANA CERRADA & MC \\
\hline ORDENACION ABIERTA ........... & $O A$ \\
\hline CIUDAD JARDIN & $\mathrm{CJ}$ \\
\hline UNIFAMILIAR AISLADA & UAS \\
\hline UNIFAMILIAR ADOSADA & UAD \\
\hline COLONIA Y TRADICIONAL POPULAR & CTP \\
\hline 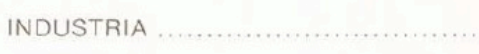 & IND \\
\hline COMERCIO & $\mathrm{CO}$ \\
\hline \multicolumn{2}{|l|}{ PROTECCION INTEGRAL } \\
\hline PROTECCION ARQUITECTONICA & Dan \\
\hline VERDE PRIVADO DE INTERES ESPE & $\odot$ \\
\hline
\end{tabular}

USOS DEL SUELO URBANIZABLE:

SUELO URBANIZ. PROGRAMADO (1\% cuatrienio)

SUELO URBANIZ. PROGRAMADO $\left(2 .^{\circ}\right.$ cuatrienio $)$

SUELO URBANIZ. NO PROGRAMADO

SUP. Y SUNP. INDUSTRIAL

SUELO NO URBANIZABLE

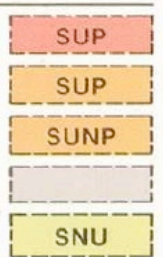

\begin{tabular}{|c|c|}
\hline \multicolumn{2}{|l|}{ GESTION DEL SUELO: } \\
\hline UNIDAD DE ACTUACION ...... & UA \\
\hline REGIMEN TRANSITORIO .... & $\mathrm{RT}$ \\
\hline PLAN ESPECIAL $\ldots \ldots \ldots \ldots \ldots \ldots \ldots \ldots \ldots \ldots \ldots \ldots \ldots \ldots \ldots$ & $\mathrm{PE}$ \\
\hline PLAN ESPECIAL REFORMA INTERIOR . & PERI \\
\hline SISTEMA GENERAL PROGRAMADO ... & $S G$ \\
\hline SISTEMA GENERAL NO PROGRAMADO & SGNP \\
\hline SISTEMA GENERAL NO URBANIZABLE & SGNU \\
\hline \multicolumn{2}{|l|}{ SISTEMAS: } \\
\hline \multicolumn{2}{|l|}{$\begin{array}{l}\text { ESPACIOS LIBRES Y ABIERTOS } \\
\text { Parque Urbano y Jardin .... }\end{array}$} \\
\hline \multicolumn{2}{|l|}{$\begin{array}{l}\text { EQUIPAMIENTO COMUNITARIO } \\
\text { Educativo }\end{array}$} \\
\hline Social - Asistencial ............. & $\mathrm{s}$ \\
\hline Deportivo ............... & $\mathrm{D}$ \\
\hline Cementerio .... & $\mathrm{C}$ \\
\hline \multicolumn{2}{|l|}{ 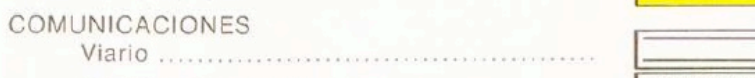 } \\
\hline Servidumbre de paso & (n) \\
\hline Aeroportuario ........... & QDIDL \\
\hline Ferroviario .............. & \\
\hline Portuario ....... & Q120 \\
\hline $\begin{array}{l}\text { TECNICOS } \\
\text { Infraestructura de Servicios }\end{array}$ & \\
\hline
\end{tabular}

Fig.7 Fragmento de la leyenda del Plan General de 1983.

El Centro Histórico ya no se representa como una bolsa única, sino que se valora su patrimonio cultural y arquitectónico con el objetivo de dotar de simbolismo los valores propios de la ciudad. Aparecen así en la leyenda conceptos como "protección integral" y "protección arquitectónica" diferenciando los valores arquitectónicos o culturales del patrimonio monumental, de los valores propiamente urbanos de las unidades vecinales construidas con anterioridad, pero que sin contener valores artísticos de relevancia, representaban buenos modelos de forma y vida urbana. Igualmente, la leyenda refleja un mayor desglose de ordenanzas, que en este caso responden al reconocimiento de tipologías existentes, y cuyo desarrollo normativo tiene un enfoque más paliativo y corrector, que programático.

La preocupación por el paisaje urbano también tiene su reflejo en el Plan, a través del catálogo de "árboles protegidos" e incluso del "verde privado de interés especial", en una clara alusión a la calidad urbana que se demanda para la ciudadanía.

La nomenclatura de las dotaciones refleja el espíritu de la época. Del "social asistencial" en tanto que servicio que se presta al área que se construye como extensión de la ciudad que encontrábamos en el Plan de 1971, pasamos a la denominación de "equipamientos comunitarios", en tanto que asistencia que se presta a la comunidad socialmente constituida. Los "campos deportivos" del Plan anterior aparecen aquí más vinculados a la vida saludable, y se nombran como "equipamiento deportivo" en una concepción más generosa de las posibilidades que esta reserva de suelo supone para la ciudad. El deporte aspiraba a convertirse en un derecho para todas las personas, y el fútbol no era el único modo de practicarlo.

E viario adquiere una dimensión más amplia que la propia funcionalidad viaria. Las carreteras pasan a englobarse dentro del epígrafe de la leyenda denominado "comunicaciones", que implica una mayor perspectiva del sentido de las infraestructura viarias, vinculadas a la posibilidad de proporcionar comunicación entre las distintas áreas urbanas, y con relación a quienes se desplazan por la ciudad: sus ciudadanos y ciudadanas.

En cuanto a la clasificación, seguimos encontrando una definición negativa del campo. La clasificación establecida por la Ley de 1975, habla de "suelo urbano", "suelo urbanizable" y "suelo no urbanizable", es decir, el suelo que tan solo se define por la negación de sus posibilidades. No obstante, encontramos ya una preocupación por los valores ambientales propios de su tiempo histórico en la categorización de las protecciones de áreas naturales de valor ambiental o simbólico. 
Aparece en este Plan una nueva colección de planos que hasta entonces no existían: los planos de gestión. En ellos la leyenda muestra un desglose minucioso de figuras y programas, que reflejan la visibilidad del proceso inmobiliario. La curva de la visibilidad de Foucault actúa en este conjunto de planos haciendo partícipe a la sociedad del modo en que la ciudad se construye y se financia.

El estudio de este Plan ayuda a comprender aquel momento histórico, pero también el tiempo posterior, dada su condición de punto de inflexión entre dos momentos históricos de gran relevancia: el desarrollismo de las décadas posteriores al II Plan de Estabilización de 1959, y el desarrollismo posterior a la integración de España en la Unión Europea.

En el Plan posterior redactado por Damián Quero en 1997 (Fig.8), observamos pocas variaciones en la leyenda respecto al Plan de 1983. Aunque la Ley del suelo había cambiado y se habían transferido las competencias del urbanismo y la ordenación del territorio a la Comunidad Autónoma, el dispositivo no había sufrido grandes cambios. Sin embargo la sociedad sí había experimentado importantes transformaciones. La actividad social de la ciudadanía había descendido notablemente. Las asociaciones vecinales habían dejado de representar el poder ciudadano, que había encontrado en el voto individual su propia representación. Quizá la continuidad del lenguaje que hallamos en la leyenda hable del abandono de una parte del dispositivo: la ciudadanía. Así, los poderes políticos y económicos asumen el control del proceso urbanizador, amparados en la legitimidad que les proporciona el marco normativo que garantiza la ley con su exposición pública y su programa de participación.

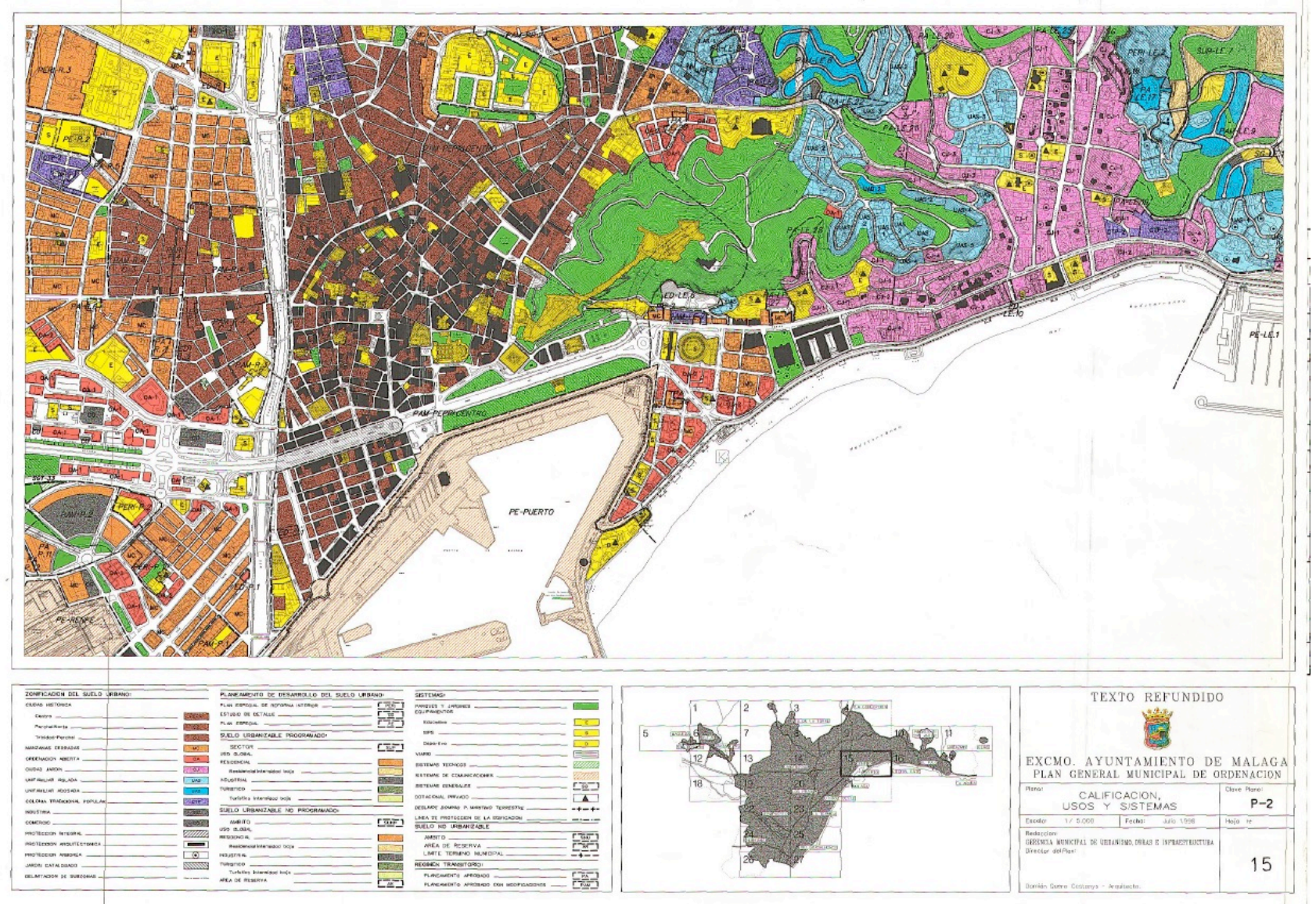

Fig.8. Plan General de Málaga. Damián Quero. 1983.

No obstante, encontramos algunos lenguajes que merecen atención. Los barrios de "vecinos" de la periferia del casco histórico considerados como áreas residenciales con valor arquitectónico en algunos casos por el Plan de 1983, se integran en este Plan dentro de la "ciudad histórica", confiriendo a este concepto un sentido más amplio, propio de la consideración del patrimonio desde una perspectiva menos monumental y formal: la ciudad histórica trasciende los límites de la antigua muralla e incluye los arrabales. Se incorpora así toda la investigación sobre el patrimonio urbano que se había realizado a raíz de la redacción del Plan Especial de Protección y Reforma Interior, enunciado por el Plan de 1983 como consecuencia de la aplicación de la ley de 1975 en relación a la delimitación 
y definición de los Planes Especiales y su consideración al patrimonio urbano y ambiental.

Encontramos además, una nueva calificación de uso global en los suelos urbanizables no programados, es decir, en aquellos que se desarrollarán en el futuro más lejano de la programación del Plan: el uso turístico. Ya era hora de que en un territorio eminentemente turístico, apareciera este uso explicitado en su normativa y en su espacialización. Es decir: en su leyenda.

En el último Plan General aprobado en Málaga, de 2011 y también redactado por Damián Quero, podemos ver una gran cantidad de incorporaciones en los planos y en sus leyendas. En el plano "Determinaciones estructurales derivadas del Plan de Ordenación del Territorio del Área Metropolitana de Málaga" (Fig.9), descubrimos algo que hasta la fecha no había existido: la referencia a un planeamiento supramunicipal. Si bien todas las leyes del suelo desde la de 1956 hablaban de la necesidad de redactar planes estatales y regionales, no fue hasta el siglo XXI cuando se redactaron planes regionales y subregionales, con determinaciones propias del ámbito territorial que abarcaban. Así, la ciudad de Málaga debía dar cumplimiento a las determinaciones del Plan de Ordenación Territorial del Área Metropolitana de Málaga, en el que se englobaba la capital y todos los municipios de su área de influencia. En este plano encontramos una leyenda que habla de protección ambiental, mostrando un lenguaje más técnico que el de los planes anteriores, incluyendo las redes de protección establecidas a nivel autonómico, estatal y europeo. Aparece la protección territorial, fruto de una concepción que sin llegar a lo autonómico, trasciende lo local, poniendo de manifiesto nuevas escalas de reflexión política y económica.

Es interesante observar cómo se localizan lo que se denominan "áreas de oportunidad", que curiosamente siempre se ubican en los suelos no urbanizables. Estas áreas permiten implantar en el suelo no urbanizable, usos tales como complejos turísticos. Se enfatiza la idea de la definición negativa del campo. La oportunidad surge siempre de asemejarse de algún modo a las posibilidades del suelo urbano o urbanizable. El lenguaje muestra aquí su dimensión de ocultamiento, al no verbalizar las posibilidades de este suelo. De nuevo, la curva de la visibilidad muestra lo que la sociedad, o los agentes que la controlan, quieren dejar ver en el suelo del campo: su imposibilidad frente a su capacidad.
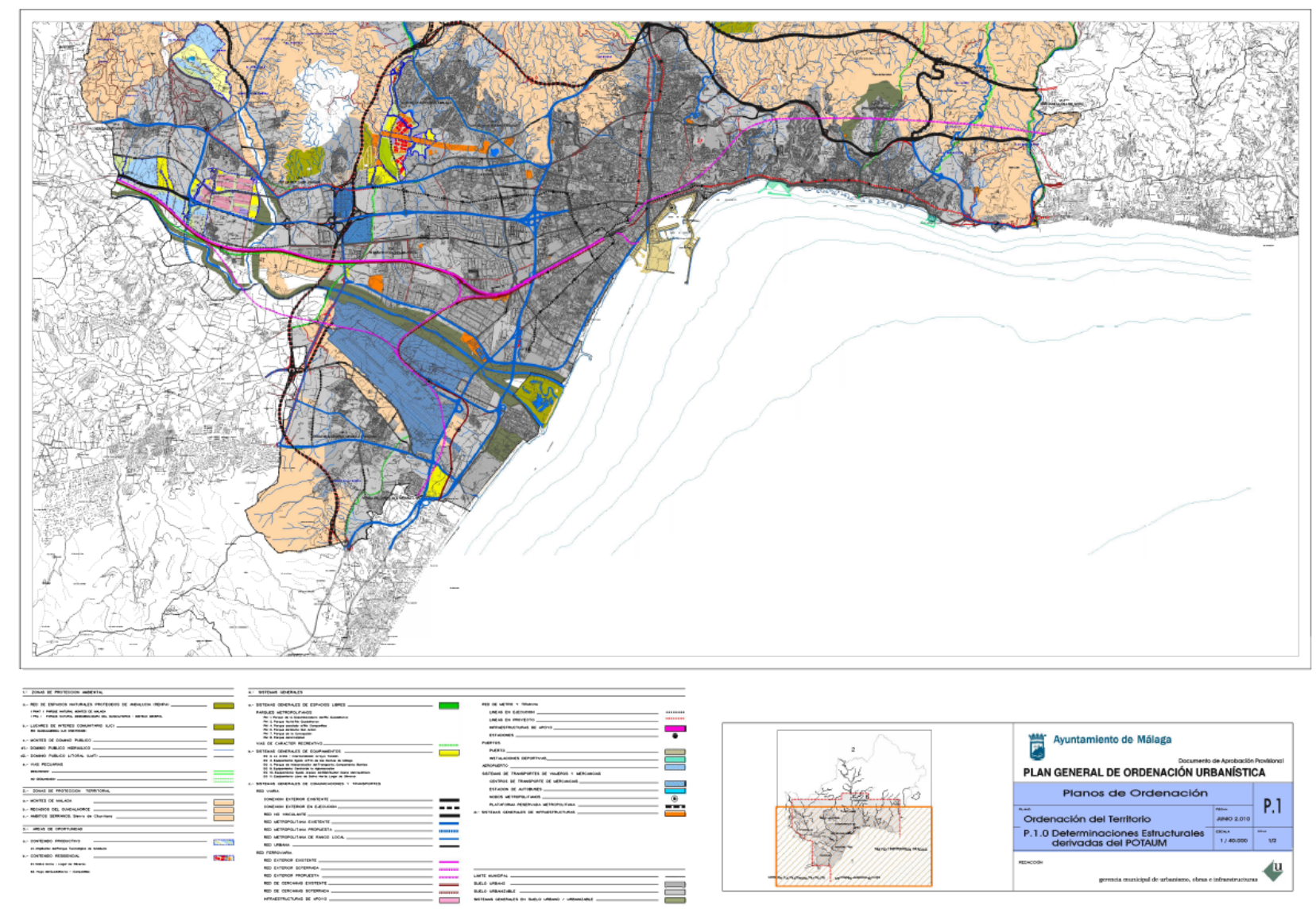

Fig.9. Plano de Determinaciones derivadas del Plan de Ordenación del Territorio del Área Metropolitana de Málaga (POTAUM), incluido en el Plan General de Málaga de 2011. 
Sin embargo, la acción de colectivos interesados por la puesta en valor del medio ambiente, se ve reflejada en otra parte de la leyenda. En la de Sistemas Generales, encontramos la denominación de "vías recreativas", así como la de "parques metropolitanos", atendiendo a la función que estos tienen en la articulación de áreas más extensas que la propia ciudad y que son disfrutadas por personas de distintos municipios como recurso recreativo y turístico.

Las redes se multiplican, pasando de la denominación "carreteras" del Plan de 1971 a la de "comunicaciones" en el Plan de 1983 y 1997, para denominarse ahora "movilidad". De nuevo, el lenguaje de los tiempos, fruto de la sensibilidad pero también de los saberes de este tiempo histórico, se representa en la leyenda del Plan.

En la ordenación, encontramos la denominación de ordenación estructural y pormenorizada. Esta diferenciación, más allá de dar cumplimiento a la Ley del Suelo de Andalucía Ley 7/2002 (que también recogen otras legislaciones autonómicas), refleja la necesidad imperiosa de concretar los ámbitos de acción de los planes y su posibilidad de flexibilización, en un momento en el que el desarrollo normativo y reglamentario, así como la garantía pretendida por la fiscalización pública de los expedientes, han hecho prácticamente inviable el desarrollo del planeamiento general. Si el urbanismo comenzó siendo una cuestión propia del Ministerio de Fomento o las Consejerías Autonómicas de Urbanismo, ahora la participación de los agentes sectoriales -costas, aguas, carreteras, medioambiente, cultura, aviación civil, salud, etc...- se ha extendido, agotando las posibilidades de acción de un instrumento nacido para resolver problemas complejos a través de las posibilidades del diseño urbano.

En la leyenda de calificación, encontramos nuevas formas de nombrar la economía contemporánea. Así desaparece el uso "industrial" para dar paso al uso productivo, empresarial -como reflejo de la "cultura del emprendimiento"- logístico, comercial u hotelero. Apenas cambian las ordenanzas del suelo urbano, cuando sin embargo, existe una gran cantidad de necesidades nuevas de habitación e incluso constructivas, como viviendas para jóvenes, investigadores, o personas que se desplazan para trabajar durante un periodo concreto de tiempo y que no encuentran una oferta adecuada en el mercado de alquiler permanente ni en el de las viviendas turísticas. Por otro lado, la irrupción de plataformas como Airbnb no puede suponer el silencio en cuanto a la regulación de las viviendas turísticas, que sin embargo no encuentra reflejo en la normativa ni en consecuencia, en leyenda de calificación y usos. Por otra parte, nuevas tipologías constructivas permitirían una ocupación sostenible y ambientalmente comprometida en el suelo "no urbanizable" pero no por ello "no disfrutable". A través de módulos residenciales no invasivos y temporales se podría favorecer el mantenimiento de los espacios agrícolas y naturales con cargo a los propietarios del suelo, a cambio permitir usos compatibles con las nuevas posibilidades de la arquitectura sostenible, temporal o efímera.

En el plano correspondiente al Suelo no Urbanizable, observamos un lenguaje propio de una gran complejidad afectada por innumerables restricciones en la forma de protecciones. Encontramos muchas afecciones sectoriales, que "afectan" al territorio, pero no lo "proyectan", pues su capacidad sectorial solo se centra en la limitación, no en la creación de un modelo para el suelo que no es urbano.

Por otra parte, las protecciones urbanas adquieren una relevancia mucho mayor, lo que se refleja en una colección específica de planos, con protecciones que atienden a la sensibilidad de una sociedad, pero también al saber de la misma. La creación de la Universidad de Málaga en 1971 puso en carga una potente maquinaria científica que investigó y puso en valor muchos elementos propios del territorio de influencia. Así, la consideración de las pinturas del siglo XIX en las fachadas de las viviendas burguesas del centro histórico como forma de expresión artística de esta sociedad, han sido consideradas en este Plan merecedoras de una protección específica. Así mismo se identifican en los planos las antiguas chimeneas del patrimonio industrial de la ciudad del siglo XIX (Fig.10). También la hallamos la localización de convenios específicos sobre áreas concretas del casco histórico, los cuales pretenden hacer transparente una gestión municipal que a veces ha quedado en entredicho en relación con la protección del patrimonio histórico de la ciudad. 
PROTECCIONES

PROTECCION INTEGRAL

PROTECCION ARQUITECTONICA 1. GRADO

PROTECCION ARQUITECTONICA 2* GRADO

PROTECCION AMBIENTAL

espacios públicos protegidos: calle o plaza

ESPACIOS PÚBLICOS PROTEGIDOS: JARDÍN

inMUEBLES CONFIRMADOS CON EXISTENCIAS PINTURAS

INMUEBLES SUSCEPTIBLES DE CONTENER PINTURAS
DELIMIT ACIONES

- -1 DELIMITACION DEL AMBITO PAM-PEPRI. CENTRO

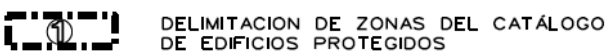

Fig.10. Fragmento de la leyenda del Plan General de Málaga de 2011.

\section{Conclusiones}

Si los diferentes Planes Generales de ordenación urbana han evidenciado a través de su leyenda una explicitación de las tensiones sociales, económicas y de poder de un determinado periodo, el caso del Plan de 2011 resulta especialmente ilustrativo. Se muestra una gran complejidad en la concepción del territorio y en su gestión, la participación de una gran cantidad de nuevos agentes sectoriales y de temáticas a considerar, tales como la protección de las pinturas de las fachadas del s.XIX, los mapas del ruido en la ciudad, o la Red Natura 2000.

También podemos concluir que el Plan de 2011 "no" visibiliza la vida de las personas. No aparecen planos que hablen de la seguridad, del miedo que pasan determinados colectivos como las personas mayores en los espacios públicos, o las mujeres en determinadas áreas poco cuidadas o iluminadas de la ciudad. No se habla de las áreas aptas para la infancia, ni de la polinización de los jardines o las avenidas arboladas, en un momento en el que existe un problema generalizado de alergia en las ciudades. No se tratan los problemas de segregación urbana, de la ocupación temporal de los espacios públicos o de las prácticas culturales de determinadas minorías. Tampoco se considera lo agradable que es un espacio o lo incómodo que resulta cuando sin embargo, existen políticas públicas que fomentan la calidad de vida en las ciudades, como el programa "La ciudad amable" de la Junta de Andalucía (Junta de Andalucía. Dirección General de Rehabilitación y Arquitectura. , s.f.). Y no se habla de ello, porque no se nombra en los planos. Y ya sabemos que lo que no se nombra no existe.

La participación ciudadana ha desaparecido absorbida por una vorágine de información elaborada sólo gracias a las posibilidades de una herramienta informática de gran potencia, como son los programas de dibujo asistido por sistemas de información geográfica y bases de datos.

Volviendo a la idea de dispositivo, encontramos cómo éstos además, tienen la función de definir dos partes. Tiqqun explica una de sus cualidades con el ejemplo de las barreras del metro parisino (Tiqqun, 2012 págs. 92-93)

"Frente a todo dispositivo, como por ejemplo las puertas de entrada del metro parisino, la pregunta incorrecta sería: “¿Para qué sirve?”. Y la respuesta incorrecta en este caso preciso: "Para impedir el fraude”. La pregunta correcta, materialista, la pregunta metafísico-crítica sería por el contrario: “¿Pero qué hace, qué operación lleva a cabo el dispositivo?". Y habrá que responder: "El dispositivo singulariza, separa los cuerpos fraudulentos de entre la masa indistinta de "usuarios" obligándolos a cierto movimiento de fácil ejecución (saltar por encima de las puertas justo detrás de un "usuario en regla"). De este modo, el dispositivo posibilita la existencia del predicado "defraudador", es decir, que posibilita la existencia de determinado cuerpo en tanto que defraudador"”'

El planeamiento de la mayor parte de las ciudades en general, ha construido un predicado. Quien lo puede entender y quien no es capaz de hablar su lenguaje. Los no instruidos en el idioma técnico, jurídico y sectorial, pasan a ser analfabetos de hecho, e incapaces de una participación efectiva en el proceso, a pesar de la ingente normativa de ámbito europeo, estatal y autonómico que promulga la participación pública en el diseño y gestión de la ciudad. 
Podemos concluir que las líneas de subjetivación están desdibujadas en este nuevo paradigma del dispositivo "planeamiento urbanístico", gracias a la ocultación de todo un lenguaje tras la ingente cantidad de datos técnicos espacializados en las planimetrías de los documentos urbanísticos.

Sin embargo, existen movimientos incipientes de colectivos, que si bien no están vinculados por relaciones de contacto vecinal como ocurría en la Transición, se articulan en torno a temáticas como los carriles bici, los caminos seguros al colegio de los niños y niñas, la protección del patrimonio no declarado, la puesta en valor del patrimonio etnológico o sonoro, la aplicación de la perspectiva de género al diseño de la ciudad, la recuperación de la condición de habitabilidad en los centros históricos gentrificados, o la visibilidad de las minorías. Sólo falta que estas líneas de subjetivación sean capaces de incidir en un dispositivo que ha actuado al margen de la subjetivación de estos colectivos o individualidades, quizá, debido al positivo efecto que supuso la experiencia del planeamiento de la década de los 80 , en las que el dispositivo se manifestó en su mejor capacidad de acción.

Se trata, en definitiva, de ser capaces de llevar a la leyenda del planeamiento urbanístico, las cuestiones que afectan a la vida de las personas en la ciudad, más allá de las limitaciones sectoriales, las posibilidades económicas del proceso inmobiliario, o las capacidades de ordenación estructural del territorio. Lo que no se nombra no existe. Tarea de los arquitectos y arquitectas contemporáneos que se sientan interpelados por las cuestiones sociales, es la de nombrar todas estas temáticas, para, a través de una nueva subjetivación individual o colectiva, provocar líneas de ruptura en el dispositivo actual, con el fin de dar lugar a un nuevo paradigma del "dispositivo planeamiento". Pero esto no se consigue gritando mucho en las redes sociales, sino conociendo bien las posibilidades técnicas de nuestra disciplina.

\section{Bibliografía.}

ÁLVAREZ CALVENTE, Miguel. “Málaga versus Guadalmedina”. Revista Jábega, 1973, núm 1, p.28-30.

DELEUZE, Gilles. “¿Qué es un dispositivo?” en Contribución a la guerra en curso. Errata Naturae Ediciones, 2012. ISBN: 978-84-15217-18-3. p.7-26.

España, Exposición de Motivos. Ley de 12 de mayo sobre régimen de suelo y ordenación urbana. Boletín Oficial del Estado, 14 de mayo de 1956, número 135.

FOUCAULT, Michel. Saber y Verdad. Ediciones La Piqueta, 1985, ISBN: 84-7443-038-0.

GARCÍA BUJALANCE, Susana "El Plan General de Málaga de 1983. Un instrumento para la trasformación urbana”. Directores: Vicente Granados Cabeza, Carlos Hernández Pezzi. Universidad de Málaga. Departamento de Técnicas de Representación Gráfica y Diseño. 2016.

Junta de Andalucía. La ciudad amable [en línea]. Dirección General de Rehabilitación y Arquitectura [ref. 20 de junio 2017]. Disponible en Internet: <http://www.juntadeandalucia.es/fomentoyvivienda/portal-web/web/areas/arquitectura/la_ciudad_amable>

LEIRA, Eduardo "Más que planes. Antecedentes y papel de los Planes Municipales en España en los primeros 80" en Diez años de planeamiento urbanístico en España: 1979-1989. Centro de Publicaciones del MOPU, 1989. ISBN: 84-7433-593-0. p. 153-162.

MACHUCA Santa Cruz, Luis. Málaga, ciudad abierta: origen, cambio y permanencia de una estructura urbana. Ediciones del Colegio de Arquitectos de Málaga, 1987, ISBN: 8439899939, 9788439899938.

MORENO PERALTA, Salvador, QUERO CASTANYS, Damián, SEGUÍ PÉREZ, José. "La ciudad y el nuevo Plan: Málaga", en Diez años de planeamiento urbanístico en España: 1979-1989. Centro de Publicaciones del MOPU, 1989. ISBN: 84-7433-593-0. p. 71-80.

ORTIZ, José y SEGUÍ, José "Málaga”. en Atlas histórico de ciudades europeas. Península Ibérica. Salvat y Centre de Cultura Contemporània de Barcelona, 1991. ISBN: 84-3455681-2. p. 291-314.

REINOSO BELLIDO, Rafael. Topografías del paraíso: la construcción de la ciudad de Málaga entre 1897 y 1959. Editorial del Colegio de Arquitectos Técnicos y Aparajeadores de Málaga. 2005, ISBN: 8487894062, 9788487894060.

SEGUÍ PÉREZ, José. “González Edo. Análisis de su obra”. Revista Geometría, 1988, núm 6, p.62-82 
TIQQUN. "Podría surgir una metafísica crítica como de ciencia de los dispositivos" en Contribución a la guerra en curso. Errata Naturae Ediciones, 2012. ISBN: 978-84-15217-18-3. p.27-120

\section{Biografía}

Susana García Bujalance. Doctora arquitecta por la Universidad de Málaga, profesora asociada del Área de Urbanismo y Ordenación del Territorio del Departamento de Arte y Arquitectura de la Universidad de Málaga. Centra su investigación en el planeamiento urbanístico y sus posibilidades actuales, la aplicación de la perspectiva de género al urbanismo, el paisaje y el turismo.

Susana García Bujalance Doctor architect by the University of Malaga, associate professor of the Area of Urban Planning and Territory of the Department of Art and Architecture of the University of Malaga. She focuses her research on urban planning and its current possibilities, the application of the gender perspective to urbanism, landscape and tourism. 